Review Article

\title{
Jatropha Oil as a Substituent for Palm Oil in Biobased Polyurethane
}

\author{
Mohamad Ridzuan Amri, ${ }^{1}$ Syeed Saifulazry Osman Al-Edrus $\mathbb{D}^{1},{ }^{1}$ Chuah Teong Guan $\mathbb{D}^{1,2}$ \\ Faizah Md Yasin, ${ }^{2,3}$ and Lee Seng Hua ${ }^{1}$ \\ ${ }^{1}$ Institute of Tropical Forestry and Forest Product, Universiti Putra Malaysia, 43400 Serdang, Selangor, Malaysia \\ ${ }^{2}$ Department of Chemical and Environmental Engineering, Faculty of Engineering, Universiti Putra Malaysia, \\ 43400 Serdang Selangor, Malaysia \\ ${ }^{3}$ Institute of Advanced Technology, Universiti Putra Malaysia, 43400 Serdang, Selangor, Malaysia
}

Correspondence should be addressed to Syeed Saifulazry Osman Al-Edrus; saifulazry@upm.edu.my

and Chuah Teong Guan; chuah@upm.edu.my

Received 29 November 2020; Revised 29 December 2020; Accepted 28 January 2021; Published 17 February 2021

Academic Editor: Mehdi Salami-Kalajahi

Copyright (c) 2021 Mohamad Ridzuan Amri et al. This is an open access article distributed under the Creative Commons Attribution License, which permits unrestricted use, distribution, and reproduction in any medium, provided the original work is properly cited.

\begin{abstract}
Polyurethanes (PUs) are unique polymers that can be tailored to suit certain applications and are increasingly used in many industrial fields. Petrochemicals are still used as the main compound to synthesize PUs. Today, environmental concerns arise in the research and technology innovations in developing PUs, especially from vegetable polyols which are having an upsurge. These are driven by the uncertainty and fluctuations of petroleum crude oil price and availability. Jatropha has become a promising substituent to palm oil so as to reduce the competition of food and nonfood in utilizing this natural resource. Apart from that, jatropha will solve the problem related to the European banning of palm oil. Herein, we review the literature on the synthesis of PUs using different vegetable oils and compare it with jatropha oil and its nanocomposites reinforced with cellulose nanocrystals. Given the potential of vegetable oil PUs in many industrial applications, we expect that they will increase commercial interest and scientific research to bring these materials to the market soon.
\end{abstract}

\section{Introduction}

For a century, mankind has exploited so many nonrenewable resources, mainly petrochemicals. Today, most of the polymer markets are petrochemical-based and have been extensively converted in numerous ways, including household raw materials for industry, generating energy, and intermediate and derivative products. This exploitation process uses a vast amount of energy and leads to various effects on the environment and ecosystems due to toxic substances. On the another hand, issues related to fluctuation and depletion supply of oil, which have pushed academicians as well as industries to find suitable biobased polymers to be used instead of petrochemical-based polymers to reduce the dependency on petroleum oil. Biorenewable polymer derived from biomass is the most possible substituent to the petro- chemical polymer. Malaysia produces more than 160 million tonnes of biomass yearly and expects to grow in the future, and those biomasses include palm oil, timber waste, coconut trunk fibers, rice husks, sugarcane waste, and municipal waste [1]. Plant-based and agriculture-based biomasses are the largest natural resources and abundantly available in Malaysia [1]. In general, biorenewable polymers created from biomass can be categorized into 3 main types: (1) polymers directly synthesized from plant-based biomass, (2) polymers synthesized from biobased monomers, and (3) polymer products from naturally or genetically modified animals/organisms [2]. Malaysia is blessed with underutilized biomass due to its unique tropical whether suitable for agriculture activities. Thus, palm oil plantation is widely planted in Malaysia and generates a substantial amount of waste every year. This waste includes empty fruit bunches, mesocarp 
fibers, palm oil fronds, palm kernel shell, palm oil trunks, and palm oil mill effluent. However, only $23 \%$ of palm oil biomass is used as a source of energy for the boiler in a palm oil mill, and the remaining $75 \%$ is underutilized and abandoned on site [3]. This value shows a stable supply of plant-based biomass which contains polysaccharides and lipids/oil to be utilized and exploited for diversified products.

Cellulose is important to human civilization and has been utilized in all kinds of practical applications for centuries. With the discovery of cellulose, its structure, morphology, and chemical composition were unknown. Improvements have been made over time, mainly through the selection and processing of its original sources and harvesting. The molecular structure of cellulose did not bring any meaning until its discovery at the beginning of the nineteenth century. Cellulose consists of linear polysaccharides with repeating units of disaccharides of $D$ glucose. The $D$ glucose is linked with $\beta-1,4$ linkage and intramolecular or intermolecular hydrogen bonding between the adjacent glucose units to form a linear chain. In plants, the majority of cell walls consist of lignin, cellulose, and hemicellulose, where they present about $10-25 \%, 35-50 \%$, and $20-25 \%$ of the dry weight of lignocellulosic biomass, respectively [4]. Examples of lignocellulosic biomass that contain high cellulose composition are jute, hardwood, softwood, and pinecone biomass.

Today, the research trend has moved toward nanosized fillers for biopolymer composites. The biopolymer composite is widely used from low-cost household products to high-end industrial production. As cellulose is one of the natural and most abundant fibers, the cellulose fiber-reinforced polymer composite has gained much attention from academicians as well as industrialists. Cellulose-reinforced polymer composite has advantages and relevant properties such as nonabrasiveness, nontoxicity, biodegradability, low density, combustibility, and less production course compared to other synthetic polymers [4]. Despite its advantages, it has some disadvantages like poor interfacial adhesion and high water adsorption. Due to this, industrials are not interested in the production of cellulose fiber-reinforced processes. Even though this issue can be solved by chemical modification of the cellulose fiber itself, but the recent trend of research is now focused more on the extraction of nanocellulose material from cellulosic fibers for the fabrication of nanocellulose fiber biocomposite application. Review of the extraction and production of nanoscale cellulose materials has been made extensively in the last decade, but their application as reinforcement fillers is a relatively new research field. When compared with cellulose, the nanocellulose material has a high surface ratio, is light weight, and is higher in strength and stiffness.

A recent study conducted by $\mathrm{Kim}$ et al. shows that by adding cellulose nanofibrils from 1-50wt\% of waterborne polyurethane, the thermal and mechanical properties of the composite film improve significantly as the loading of cellulose nanofibrils increases [5]. Same trends were also observed in the work conducted by Zhang et al. and Kaushik et al. in which $1-15 \%$ of CNF in the starch natural polymer was incorporated $[6,7]$. It is proven that, by all past studies conducted, cellulose nanofibers can increase the mechanical properties and are suitable to be used as reinforcement filler for biopolymers.

In Malaysia, the agriculture sector contributes about 7.3\% (RM 99.5 billion) to Malaysia's gross domestic product (GDP) in 2018; meanwhile, palm oil was the major contributor to the GDP of the agriculture sector by as much as $37.9 \%$. This achievement is due to Malaysia having produced millions of tonnes of crude palm oil and palm kernel oil throughout the year 2018. However, to utilize this availability of natural resources, some issues arise as using edible oil to serve nonfood products is not appropriate. The use of edible oil as a feedstock will increase and create competition and conflicts of interest in terms of demand and supply between food and nonfood industries. This will affect the price growth and insufficient supply of palm oil. Apart from that, there is an issue arising about the banning of international trade of palm oil by the European Union from commodity countries such as Malaysia and Indonesia. This banning is aimed at reducing tropical deforestation and forest degradation in developing countries to limit global warming and preserve biodiversity [8]. It is estimated that globally between 2001 and 2015 , about $27 \%$ of all forest disturbance was commodity-driven, and palm oil production is one of the examples that are implicated in countries such as Indonesia and Malaysia $[9,10]$. Realizing this, since 2017, Malaysia had moved to the plantation of Jatropha curcas for nonedible oil production purposely to serve nonfood product production and avoid tropical deforestation and forest degradation.

Polyurethane (PU) is one of the possible products that can be created from vegetables. PU is a green material, a high-performance elastomer, and has been applied in a wide range of engineering fields such as automotive, construction, and electrical appliances [11]. PU has various properties and can be tailor-made to suit each research application by selecting different monomers and chain extenders for synthesis or by blending special reinforcement materials. Recently, many studies reveal the use of vegetable oil especially jatropha oil for the production of polyols and polyurethane, such as producing jatropha oil-based polymer via epoxidation and ringopening [12], polyurethane as a wood adhesive [13], jatropha oil-based polyurethane as nonaqueous solid polymer electrolyte [14], and jatropha oil-based waterborne polyurethane dispersion [15]. Briefly, this paper will review and compare a few chemical processes and their parameters to produce a vegetable-based polyol as an intermediate for biobased polyurethane. As biobased polyurethane is weak in terms of mechanical and thermal properties, we will review the potential of nanocellulose materials as reinforcement and highlight its enhancement in terms of thermal and mechanical, and lastly, we highlight the finding of numerous studies which show promising nanocomposite film-reinforced cellulose nanomaterials. Overall, the overview is illustrated in Figure 1.

\section{Vegetable Oil-Based Polyurethane}

Polyurethanes (PUs) are a unique class of polymers which exhibit an excellent range of properties and applications in elastomers, adhesives, sealants, and foams [16-18]. PU is synthesized by the reaction between isocyanate and polyol. 


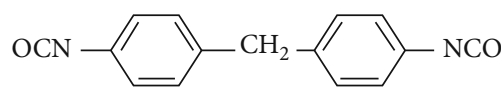

MDI<smiles>Cc1cc(Cc2ccc([N+](=O)[O-])c(C)c2)ccc1[N+](=O)[O-]</smiles>

DMMDI<smiles>Cc1cc(-c2ccc([N+](=O)[O-])c(C)c2)ccc1[N+](=O)[O-]</smiles>

TODI<smiles>CCc1cc(-c2ccc([N+](=O)[O-])c(CC)c2)ccc1N=O</smiles>

DADI

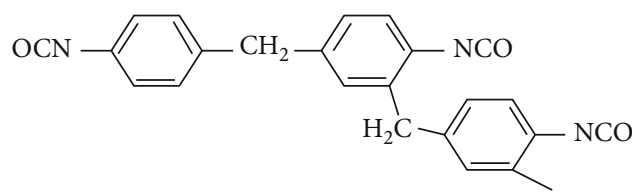

Polymeric MDI<smiles>Cc1ccc(N=O)cc1[N+](=O)[O-]</smiles>

2,4-TDI<smiles>Cc1c(N=O)cccc1N=C=O</smiles>

2,6-TDI<smiles>O=CNCCCCCCN=O</smiles><smiles>O=[N+]([O-])c1cccc([N+](=O)[O-])c1</smiles><smiles>CC1(C)CC(N=O)CC(C)(CN=O)C1</smiles>

IPDI

FIGURE 1: Overall flowchart.

Sometimes, low molecular weight diols or amines are used to increase the PU molecular weight. The specific application requires a specific character of polymer. The structure of the resulting polymers can be adjusted to manually selecting and controlling appropriate reacting components. A variety of polyols are widely available; meanwhile, only a few polyisocyanates are commercially available [19]. Figure 2 shows some commonly used isocyanates for PU synthesis. Properties of the created PUs are highly dependent on the selection of polyols. Vegetable oil-based polyols act as soft amorphous segments that provide flexibility to the created PU, while cyclic isocyanates act as hard segments providing mechanical strength. These combinations of hard and soft segments give an excellent combination of properties to the created PU, including degradation, mechanical strength, elasticity, and toughness [20]. Besides that, the selection of suitable vegetable oil as a soft segment of polyurethane gives a significant impact to its properties. As of today, soybean oil is the world's largest vegetable oil used by industries for various applications. As for Malaysia, it is still dependent on palm oil. Jatropha oil is a promising candidate to replace palm oil for polyurethane production in Malaysia. This is because its chemical composition is much better than palm oil. The chemical composition is summarized in Table 1 .

2.1. Vegetable Oil-Based Polyol Prepared by Epoxidation/ Oxirane Ring-Opening and Their Resulting PUs. Of all common vegetable oils, castor oil naturally contains hydroxyl groups which makes it the absolute choice to produce PU. However, the resource of castor oil is only available in the American region and is not suitable to be planted in Malaysia. The most commercially used synthesis method of vegetable-based polyols is by epoxidation and the ring-opening method. Epoxidation and ring-opening have become the main reaction route for the synthesis of vegetable-based polyols because of its advantages in terms of economic and safety, as the reaction can be performed at a lower temperature which is between $25^{\circ} \mathrm{C}$ and $80^{\circ} \mathrm{C}$. On another hand, hydroformylation requires expensive catalysts and needs to be conducted at high pressure and temperature, $14-28 \mathrm{MPa}$ and $90-120^{\circ} \mathrm{C}$, respectively. Meanwhile, ozonolysis produced polyols with a lower hydroxyl number with a maximal functionality of 3 . Here, the recent advances related to epoxidation and the ringopening reaction of vegetable oil will be reviewed. Comparison between these methods is summarized in Table 2 and reviewed in detail in this section.

Several research groups have conducted a systematic study on the kinetics of ring-opening reactions. Guo et al. [23] reported that epoxidized palm oil was successfully ring-opened by acetic acid without a catalyst and showed that its activation energy was $40.28 \mathrm{~kJ} / \mathrm{mol}$. Zhang et al. showed a comparable result of activation energy with Guo et al. [24] by using the same ring opener but used soybean oil instead of palm oil. On another hand, Zhang et al. [25] utilized the natural hydroxyl group located at the castor oil fatty acid chain 


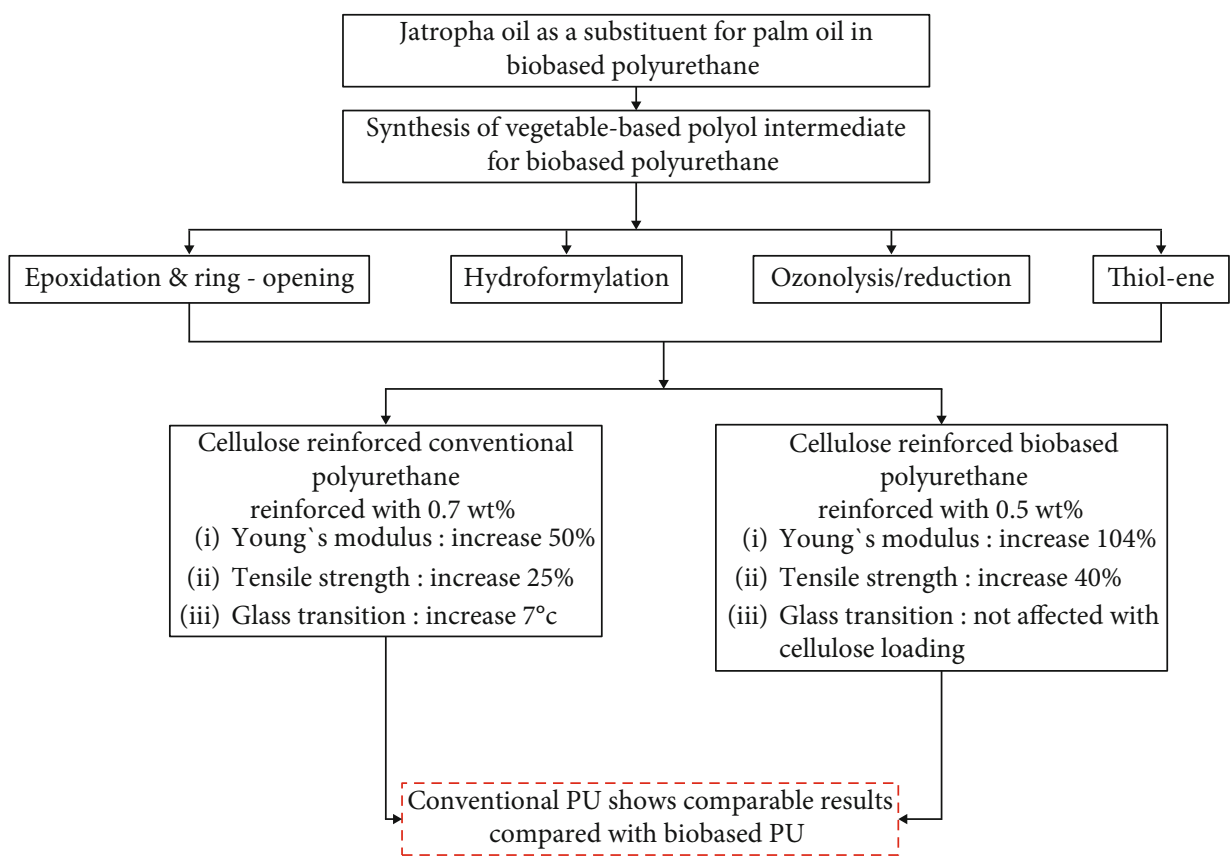

Figure 2: Chemical structure of commonly used isocyanates [24].

TABLE 1: Chemical composition comparison of fatty acid profile.

\begin{tabular}{|c|c|c|c|c|c|c|c|}
\hline Fatty acid & Jatropha oil $^{\mathrm{a}}$ & \multicolumn{2}{|c|}{ Palm oil ${ }^{\mathrm{a}, \mathrm{b}}$} & Coconut oil $^{\mathrm{b}}$ & Sunflower oil ${ }^{\mathrm{b}}$ & Soybean oil $^{\mathrm{b}}$ & Pongamia oil $^{\mathrm{b}}$ \\
\hline Caprylic acid (C8:0) & - & \multicolumn{2}{|c|}{-} & 8 & - & - & - \\
\hline Capric acid (C10:0) & - & \multicolumn{2}{|c|}{ - } & 8 & - & - & - \\
\hline Lauric acid (C12:0) & - & - & - & 48 & 0.5 & - & - \\
\hline Myristic acid (C14:0) & 0.38 & 3.5 & - & 16.0 & 0.2 & 0.1 & - \\
\hline Palmitic acid (C16:0) & 16.0 & 39.5 & 40.3 & 8.5 & 4.8 & 11.0 & 9.8 \\
\hline Palmitoleic acid $(16: 1)$ & $1-3.5$ & - & - & - & 0.8 & 0.1 & - \\
\hline Stearic acid $(\mathrm{C} 18: 0)$ & $6-7$ & 3.5 & 3.1 & 2.5 & 5.7 & 4.0 & 6.2 \\
\hline Oleic acid (C18:1) & $42-43.5$ & 46 & 43.3 & 6.5 & 20.6 & 23.4 & 72.2 \\
\hline Linoleic acid (C18:2) & $33-34.5$ & 7.5 & 13.2 & 2.0 & 66.2 & 53.2 & 11.8 \\
\hline Linolenic acid (C18:3) & 0.8 & - & - & - & 0.8 & 7.8 & - \\
\hline
\end{tabular}

Taken from Verma and Gaur [21]; ${ }^{\mathrm{b}}$ taken from Koh and Mohd Ghazi [22].

TABLE 2: Comparison of commonly used methods for vegetable oil-based polyols.

\begin{tabular}{lcccc}
\hline & Epoxidation/ring-opening & Ozonolysis/reduction & Hydroformylation & Thiol-ene \\
\hline Number of steps & 2 & 2 & 2 & 1 \\
Functionality & Secondary, tunable & Terminal, 3 & Primary, tunable & Primary, tunable \\
OH value & $70-320$ & $228-260$ & $150-200$ & 223 \\
MW & Variable $(>1000)$ & $500-700^{\text {a }}$ & $900-1100^{\text {a }}$ & $1070-1440^{\text {a }}$ \\
Viscosity & High & Low & Medium & Medium \\
Reaction temperature & Variable (50-170) & RT & Low or RT \\
Reaction time & Long & Medium & Short \\
\hline
\end{tabular}

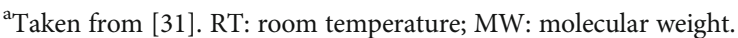

as a ring opener for epoxidized soybean oil with the presence of 1,8-diazabicycloundec-7-ene as a catalyst and showed that the activation energy was $72.2 \mathrm{~kJ} / \mathrm{mol}$. Based on this finding, it can be concluded that higher activation energy is due to the steric effect of long carbon chains. As a solution for high activation energy, a suitable catalyst and reaction temperature can be used to lower it down and thus achieve faster reaction time. 
Another type of ring opener that is widely used is water and alcohol (mono-/polyhydroxy) and is widely catalyzed is phosphoric acid, sulphuric acid, fluoroboric acid, and Lewis acid $[23,26]$. Using a different ring opener, which is methanol glycol and 1,2-propanediol, Ni et al. [27] produced a soybean oil-based polyol with $\mathrm{OH}$ number in the range of 148 to $240 \mathrm{mg} \mathrm{KOH} / \mathrm{g}$. What makes the $\mathrm{OH}$ number important is because it correlates with the crosslink density between isocyanate and polyol. PUs with glassy properties were usually created from polyols with $\mathrm{OH}$ numbers above $170 \mathrm{mg} \mathrm{KOH} / \mathrm{g}$ (high crosslink density) while PUs with $\mathrm{OH}$ numbers below $170 \mathrm{mg} \mathrm{KOH} / \mathrm{g}$ were rubbery (low crosslink density). In addition, as the $\mathrm{OH}$ number increases, the glass transition temperature and mechanical properties increase [28]. Hazmi et al. [12] successfully synthesized jatropha oil-based polyols with $\mathrm{OH}$ numbers ranging from 171 to $179 \mathrm{mg} \mathrm{KOH} / \mathrm{g}$ by using methanol as a ring opener. The authors used $50 \%$ concentrated hydrogen peroxide during the solvent-free epoxidation process and determined that concentrated hydrogen peroxide accelerated the epoxidation reaction, thus resulting in the maximum value of oxirane oxygen content and minimum side reaction. However, another study conducted by Saalah et al. [15] which used 30\% hydrogen peroxide and methanol as the ring opener shows that concentrated hydrogen peroxide does not affect the $\mathrm{OH}$ number but affects only the reaction time. The authors successfully synthesized jatropha oil-based polyols with $\mathrm{OH}$ numbers varying from 138 to $217 \mathrm{mg} \mathrm{KOH} / \mathrm{g}$ with the minimum side reaction proven by FTIR spectra. Zieleniewska et al. [29] used diethylene glycol as a ring opener for epoxidized rapeseed oil, followed by the synthesis of a porous polyurethane scaffold. The authors concluded that this scaffold is a good potential candidate as a substrate for bone tissue culture based on simulated body fluid testing. A suitable candidate is due to bioactivity and degradation behavior.

Apart from using chemical hydroxyl groups, water also was used as a ring opener as it is a cheap, highly available, and green nucleophilic reagent. Gaikwad et al. [30] reported that epoxidation and ring-opening process can be done in a single step by using a mixture of formic acid and hydrogen peroxide, in which water acts as a ring opener. Meanwhile, Kim et al. [5] synthesized palm oil-based polyols using tetrafluoroboric acid as a catalyst and water as a ring opener through epoxidation and ring-opening process. The created polyurethane exhibited a tensile strength of $6.05 \mathrm{MPa}$, elongation at break $62.05 \%$, and a glass transition temperature of $25^{\circ} \mathrm{C}$. The mechanical and thermal properties of vegetable-based polyol PUs synthesized via epoxidation and different types of ring-opening are summarized in Table 3. Hence, it is concluded that the properties of PU are influenced by the formulation of the polyol hydroxyl number, ring opener, and type of isocyanate.

In contrast, polyols prepared by ozonolysis/reduction produce primary alcohol which is more reactive compared to secondary alcohol produced by epoxidation and ringopening [32]. During hydrolysis, unsaturated carbon reacted with ozone and unstable ozonide is formed. At this stage, polyols can be produced in 3 simple steps. Unstable ozonide leads to cleavage of the unsaturated carbon in the fatty acid chains, followed by reduction to an aldehyde, and lastly to alcohol [33-37]. In addition, the resulting PU from this ozonolysis step is a rigid PU due to the hydroxyl group being located at the end of the fatty acid chain [38]. Three different models of ozonolysis from 3 different vegetable oils were successfully developed by Husic et al. [39]. Those vegetable oils were triolein oil, canola oil, and soybean oil. Based on that model, the functionalities of these polyols were 3.0, 2.8, and 2.5 , and the $T_{g}$ of the resulting PU were $53^{\circ} \mathrm{C}, 36^{\circ} \mathrm{C}$, and $22^{\circ} \mathrm{C}$, respectively. Based on this, different and residual saturated fatty acid PUs from canola and triolein polyol were glassy as shown by its elongation at break which was $51 \%$ and $25 \%$, respectively. In contrast, the elongation of PU from soybean is $176 \%$ indicating that it is a hard rubber. The functionality of polyols prepared by epoxidation/ring-opening can be tunable by varying the choice of vegetable oil with different epoxy content and ring-opening agent. Meanwhile, polyols obtained by ozonolysis/reduction are limited to a maximum of three hydroxyl groups per triglyceride [24].

Apart from ozonolysis/reduction, vegetable oil-based polyols with primary alcohol can also be produced by hydroformylation of unsaturated carbon into aldehyde using syngas in the presence of catalyst followed by reduction into hydroxyls by hydrogenation [29]. Catalysts used are rhodium with a conversion rate of about $95 \%$ but costly [40]. Based on studies conducted by Petrović et al. [41], the authors prepared crude alga oil-based polyol by hydroformylation with rhodium as catalyst $\mathrm{Rh}(\mathrm{CO})_{2}$ and compared the results with alga polyols prepared by ozonolysis and epoxidation. Epoxidation produced polyols with brown color with a hydroxyl value of around $150 \mathrm{mg} \mathrm{KOH} / \mathrm{g}$. PU produced from this process led to a red colored transparent sheet with $T_{g}$ of $-39^{\circ} \mathrm{C}$, a good tensile strength of $6.8 \mathrm{MPa}$, and $38 \%$ elongation at break. Hydroformylation produced polyols with black color with an $\mathrm{OH}$ value of $150 \mathrm{mg} \mathrm{KOH} / \mathrm{g}$. A black film was prepared with the properties of $T_{g}$ of $-36^{\circ} \mathrm{C}$, tensile strength of $8.1 \mathrm{MPa}$, and elongation at break of $28 \%$. Polyol from ozonolysis is light colored but with a low hydroxyl value. This low hydroxyl number indicated that this polyol made from ozonolysis was not suitable for polyurethane application due to the low unsaturation of algal oil.

Thiol-ene reaction provides direct conversion of vegetable oil to polyol with less side reaction, high yields, and high conversion rate [42-44]. Thiol-ene reactions consist of 3 steps: (1) formation of free radicals by thermal initiation or photoirradiation, (2) formation of thiyl radicals by transferring free radicals to the sulphur atom, and (3) antiMarkovnikov addition of thiyl radicals to double bonds [45]. Desroches et al. [46] studied the effect of radiation intensity, thiol/double bond ratio, and the number of double bonds per chain on the optimization of rapeseed oil polyols. The glass transition and thermal stability were comparable to those of a commercial polyol Desmophen 1150 (OH value: $165 \mathrm{mg} \mathrm{KOH} / \mathrm{g})$. However, the drawback of this method is the low reactivity of internal double bonds of vegetable oils, which make the thiol-ene rate for vegetable oil-based polyol limited. Tables 2 and 4 summarize the difference in each process parameter and the mechanical and thermal properties of biobased polyol produced from different vegetable oils. 
TABLE 3: Mechanical and thermal properties of vegetable-based polyol polyurethane synthesized via epoxidation and ring-opening.

\begin{tabular}{|c|c|c|c|c|c|c|c|c|}
\hline & & Polyols & & & PUs & & & \\
\hline & Ring opener & $\begin{array}{c}\text { Epoxidized } \\
\text { vegetable oil }\end{array}$ & $\begin{array}{l}\text { OH number } \\
(\mathrm{mg} \mathrm{KOH} / \mathrm{g})\end{array}$ & $\operatorname{DSC} T_{g}\left({ }^{\circ} \mathrm{C}\right)$ & $\begin{array}{l}\text { Tensile strength } \\
\qquad(\mathrm{MPa})\end{array}$ & $\begin{array}{c}\text { Elongation at } \\
\text { break }(\%)\end{array}$ & $\begin{array}{l}\text { Modulus } \\
\text { (MPa) }\end{array}$ & Reference \\
\hline & Methanol & Jatropha oil & $161-217$ & & 4 & 84.9 & 27.9 & {$[15]$} \\
\hline$A 1$ b & Methanol & Jatropha oil & $171-176$ & - & - & - & - & {$[12]$} \\
\hline Alconol & Methanol & Jatropha oil & - & - & 0.41 & 341 & 1.31 & {$[2]$} \\
\hline & Glycol & Soybean & $195-240$ & $60-75$ & $11.1-116.9$ & $32.8-36.4$ & - & {$[47]$} \\
\hline & Lactic acid & Soybean oil & 309.6 & $9.6-20.4$ & $9.3-27.1$ & $74.1-110.7$ & $4.4-12.7$ & {$[48]$} \\
\hline Acid & Phthalic acid & Palm oil & $73-80$ & - & - & - & - & [49] \\
\hline & Acetic acid & Soybean & - & 43 & 23.7 & 7.4 & 977 & [49] \\
\hline$\Delta$ ming & Propanolamine & Soybean & 317 & 29 & 9.3 & 140.8 & - & {$[50]$} \\
\hline Amme & Diethyl amine & Soybean & 67.8 & 26 & 7.8 & 24.7 & 184.7 & {$[51]$} \\
\hline
\end{tabular}

\section{Cellulose as Versatile Fiber Reinforcement for Polymer Composite}

Today, most composites were reinforced with synthetic fibers and have been applied in multiple applications such as aircraft and automation industries. However, the biggest disadvantage of synthetic fiber is its nonbiodegradability; the manufacturing process releases carbon dioxide which brings impact on the environment, and it always depends on nonrenewable resources. Therefore, inorganic biofiller has attracted much attention as it is renewable. Most documented works focused on lignin and cellulose. Here, the recent advances related to cellulose as a versatile reinforcement for polymer-based composites will be reviewed.

Based on the work conducted by Pei et al. [52], polyurethane/cellulose nanocrystal nanocomposites with ultrahigh tensile strength were successfully synthesized. Polytetramethylene glycol was used as a polyol. A cellulose nanocrystal was covalently bonded to a hard segment of polyurethane. The authors concluded that this bonded cellulose with hard segment polyurethane is important to stiffening and toughens the thermoplastic polyurethane. In addition, with the addition of only $1 \mathrm{wt} \%$ cellulose nanocrystals, the authors obtained a polyurethane nanocomposite with a tensile strength of 61.5 MPa, strain-to-failure of $994.2 \%$, and Young's modulus of 42.4 MPa. Meanwhile, Kupka et al. [53] utilized cellulose nanocrystals (CNCs) as nanofiller in a polyurethane matrix. In this work, CNCs modified by grafting polyethylene glycol (PEG) on the CNC surface (CNC-PEG) were used and compared with CNCs in the native state. The authors concluded that CNC-PEG composites showed an improved modulus up to $50 \%$ and strength up to $25 \%$ compared to CNCs by incorporating only $0.24 \mathrm{vol} \%$ of CNC-PEG. The matrix $T_{g}$ increased by up to $7^{\circ} \mathrm{C}$ with just 0.7 vol\% of CNC-PEG, indicating reduced polymer mobility close to CNC-PEG surface arising from excellent CNC-PEG dispersion and strong interfacial interactions. TEM showed excellent dispersion of CNC-PEG in the $\mathrm{PU}$ matrix compared to $\mathrm{CNC}$, presumably due to better interactions between the matrix and the CNC-PEG surface. Interestingly, the cellu- lose used by both Pei et al. [52] and Kupka et al. [53] was from the acid hydrolysis of Whatman No. 1 cellulose filter paper, and the same casting method was used. In brief, CNC was extracted from cotton $20 \mathrm{~g}$ Whatman No. 1 cellulose paper by acid hydrolysis, using $175 \mathrm{ml}$ of $64 \mathrm{wt} \%$ sulphuric acid for 1 hour at $45^{\circ} \mathrm{C}$. Then, the suspension was washed with deionized water, and the resultant precipitate was rinsed and dialyzed against water. The microcrystallites were further dispersed by ultrasonic treatment to create cellulose crystals of colloidal dimension. The detail parameters were described in the literature [52].

Khadivi et al. [54] studied the relationship of cellulose and polyurethane nanocomposite toward microphase separation. By adding $\mathrm{CNCs}$, nanoparticles prevented the formation of hydrogen bonding between PU chains affected by the presence of hydroxyl groups on the surface of CNCs. The addition of CNC made significant changes in the microphase separation of PU such as the size of phases and morphology and creates smaller droplets with irregular shapes. The authors concluded that the addition of CNCs improved the tensile modulus of nanocomposites compared to neat $\mathrm{PU}$ due to the hard nature of CNCs and its reinforcement effect in the matrix, increasing the crosslinking density due to the reaction of hydroxyls on the surface of $\mathrm{CNC}$ with isocyanate groups. Nanocellulose was fabricated using acid hydrolysis of microcrystalline cellulose, and PEG was used as a polyol. Kim et al. [5] studied the influence of cellulose nanofibrils on the microstructures and physical properties of waterborne polyurethane-based nanocomposite films. Based on the authors work, the glass transition temperature of soft segments $\left(T_{g}, \mathrm{SS}\right)$ decreased slightly with increase of the CNF content, whereas the $T_{g}$,HS values of WPU hard segments increased significantly with the increment of the CNF content up to $\sim 7 \mathrm{wt} \%$, which is caused by the presence of specific interactions between CNFs and WPU hard segments. For thermal degradation, the degradation temperature of both soft and hard segments increases as CNF increases. Interestingly, the final residues of the nanocomposite films at $800^{\circ} \mathrm{C}$ increased from $1 \mathrm{wt} \%$ to $19 \mathrm{wt} \%$ as CNF increases. However, no mechanical property change was reported. 
TABLE 4: Mechanical and thermal properties of biobased polyols produced from different vegetable oils. These polyols were then used to synthesize PU.

\begin{tabular}{|c|c|c|c|c|c|c|c|c|}
\hline \multirow{2}{*}{$\begin{array}{l}\text { Polyol } \\
\text { Type of } \\
\text { reaction }\end{array}$} & \multirow[b]{2}{*}{ Vegetable oil } & \multirow[b]{2}{*}{$\mathrm{OH}$ value } & \multicolumn{6}{|c|}{$\mathrm{Pu}$} \\
\hline & & & Isocyanate & $\begin{array}{l}\text { Glass transition } \\
\text { temperature } \\
\left(T_{g}\right)\left({ }^{\circ} \mathrm{C}\right)\end{array}$ & $\begin{array}{l}\text { Tensile } \\
\text { strength } \\
(\mathrm{MPa})\end{array}$ & $\begin{array}{c}\text { Elongation } \\
\text { at break } \\
(\%)\end{array}$ & $\begin{array}{l}\text { Young's } \\
\text { modulus } \\
(\mathrm{MPa})\end{array}$ & References \\
\hline \multirow{12}{*}{ EPO \& RO } & Jatropha & $138-217$ & IPDI & $\mathrm{NF}^{\mathrm{a}}$ & $1.8-4.0$ & $85-325$ & $1-28$ & {$[15]$} \\
\hline & Sunflower & 402 & HDI \& IPDI & $46-86$ & $1.6-4.1$ & $10.6-56.6$ & $52.1-302.3$ & {$[55]$} \\
\hline & Soybean & 309 & HDI & $9.6-24.9$ & $9.3-27.1$ & $74.1-110.7$ & $\mathrm{NF}^{\mathrm{a}}$ & [48] \\
\hline & Soybean & $61-97$ & MDI & $65-75$ & $11-32$ & $101-310$ & $\mathrm{NF}^{\mathrm{a}}$ & {$[56]$} \\
\hline & $\begin{array}{l}\text { Soybean, castor, linseed, } \\
\text { canola, \& grapeseed }\end{array}$ & $109-173$ & IPDI & $22.9-54.5$ & $0.4-29.1$ & $11-98$ & $0.8-495$ & {$[57]$} \\
\hline & Soybean & $158-283$ & MDI & $22-62$ & $3.4-39.7$ & $15-35$ & $32-351$ & {$[58]$} \\
\hline & Soybean & $\mathrm{NF}^{\mathrm{a}}$ & MDI & $43-52$ & $23.7-35.9$ & $6.1-7.4$ & $954-1284$ & [59] \\
\hline & Canola and sunflower & $259-286$ & MDI & $86-101$ & $55-60$ & $5.6-6.4$ & $1.5-1.73$ & {$[60]$} \\
\hline & Soybean & $148-237$ & TDI & 83.6 & $6.3-38.1$ & $14.5-19.6$ & $\mathrm{NF}^{\mathrm{a}}$ & {$[28]$} \\
\hline & Soybean & $124-183$ & IPDI & $24-69$ & $3.5-20.1$ & $\begin{array}{l}104.0- \\
232.7\end{array}$ & $5.6-303.7$ & {$[61]$} \\
\hline & $\begin{array}{l}\text { Soybean, linseed, corn, and } \\
\text { peanut }\end{array}$ & $139-163$ & IPDI & -9 to 13 & $2.4-7.5$ & $312-343$ & $5.20-16.1$ & {$[62]$} \\
\hline & Soybean & $99-460$ & IPDI & $50-82$ & $4.5-13.8$ & $16-109$ & $13-299$ & {$[63]$} \\
\hline \multirow{6}{*}{$\mathrm{RO}$} & Soybean & $63-81$ & IPDI & -23 to 26 & $4.6-12.4$ & $8.4-46$ & $\mathrm{NF}^{\mathrm{a}}$ & {$[63]$} \\
\hline & Soybean & 160 & IPDI & $6.6-14.4$ & 11.6 & 232.7 & 5.8 & {$[25]$} \\
\hline & Soybean & 317 & HDI & $24.36-28.69$ & $2.74-27.76$ & $140-168$ & $\mathrm{NF}^{\mathrm{a}}$ & {$[50]$} \\
\hline & Soybean \& linseed & $353-434$ & MDI & $23.7-52.3$ & $19.7-35.1$ & $9.5-90.4$ & $\mathrm{NF}^{\mathrm{a}}$ & {$[25]$} \\
\hline & Soybean \& linseed & $150-215$ & IPDI & $19.0-56.3$ & $8.6-17.2$ & $62-210$ & $67.2-315$ & {$[64]$} \\
\hline & Palm & $60-100$ & IPDI & $\mathrm{NF}^{\mathrm{a}}$ & $0.05-0.07$ & $51-74$ & $0.09-0.2$ & {$[65]$} \\
\hline \multirow{9}{*}{ Thiol } & Rapeseed & $165-223$ & HDI \& MDI & 25 to -25 & $\mathrm{NF}^{\mathrm{a}}$ & $\mathrm{NF}^{\mathrm{a}}$ & $\mathrm{NF}^{\mathrm{a}}$ & {$[46]$} \\
\hline & Castor and soybean & $203-278$ & MDI & $100-150$ & 13.07 & $\mathrm{NF}^{\mathrm{a}}$ & $\mathrm{NF}^{\mathrm{a}}$ & {$[66]$} \\
\hline & Soybean & 199 & MDI & 41 & 15.7 & 471 & 471 & {$[67]$} \\
\hline & Soybean & $119-198$ & MHI & $12-17$ & $8.1-16.8$ & $605-800$ & $605-800$ & {$[68]$} \\
\hline & Jojoba & $\mathrm{NF}^{\mathrm{a}}$ & HDI \& MDI & -18 to -43 & $\mathrm{NF}^{\mathrm{a}}$ & NF & NF & [69] \\
\hline & Castor & $218-290$ & $\begin{array}{l}\text { XDI, MDI, } \\
\text { \& HDI }\end{array}$ & $16-54$ & $2.5-43.9$ & $4-112$ & $4-112$ & {$[70]$} \\
\hline & Castor & $\mathrm{NF}^{\mathrm{a}}$ & IPDI & $18-41$ & $6-24$ & $45-401$ & $45-401$ & {$[71]$} \\
\hline & $\begin{array}{l}\text { Linseed, Olive, grapeseed, } \\
\text { castor, canola, \& corn }\end{array}$ & $190-305$ & IPDI & $23-50$ & $1-11$ & $3-204$ & $3-204$ & {$[72]$} \\
\hline & $\begin{array}{c}\text { Olive, linseed, rice bran, \& } \\
\text { grapeseed }\end{array}$ & 190-305 & IPDI & $8.7-56.9$ & $4.7-50.7$ & $15-331$ & $15-331$ & [73] \\
\hline
\end{tabular}

Abbreviations: IPDI: isophorone diisocyanate; XDI: m-xylylene diisocyanate; TDI: toluene diisocyanate; HDI: hexamethylene-1,6-diisocyanate; MDI: methylene diphenyl diisocyanate; MHI: $4,4^{\prime}$-methylenebis (cyclohexyl isocyanate). ${ }^{\text {a }}$ The corresponding data was not reported by authors.

In conclusion, the types of polyol for conventionalbased does not bring any significant effect toward the properties of polyurethane; however, it eases the synthesis process as its chemical structure is a straight line compared to nonconventional based. What is important is the hydroxyl number. High hydroxyl number will contribute to the high crosslink between isocyanate and polyol which will result in its good mechanical properties. The higher crosslink density in PUs made with polyols with $\mathrm{OH}$ numbers above $170 \mathrm{mg} \mathrm{KOH} / \mathrm{g}$ resulted in glassy properties, while PUs with lower crosslink densities with hydroxyl numbers lower than $170 \mathrm{mg} \mathrm{KOH} / \mathrm{g}$ were rubbery [24]. Apart from that, it is proven that cellulose does help to strengthen the mechanical properties of the nanocomposite film as per the above discussion. However, too much CNC loading leads to agglomeration in the $\mathrm{PU}$ matrix. The optimum loading for $\mathrm{CNC}$ is about $0.5 \mathrm{wt} \%$. Based on the work conducted by Khadivi et al. [54], $0.5 \mathrm{wt} \%$ showed microphase mixing in which CNC is well dispersed and placed between HS-rich regions. Cellulose is 
used in a wide range of applications. Table 5 shows a short review on cellulose nanocomposites in different industries.

\section{Cellulose as Versatile Fiber Reinforcement for Biobased Polyurethane Composite}

Gao et al. [84] developed waterborne castor oil-based PU nanocomposites with cellulose nanocrystals as reinforcement. The resulting PU shows that the tensile strength and Young's modulus of the composites increased by $125 \%$ and $104 \%$, respectively, with $1 \mathrm{wt} \%$ nanocrystals. This is due to their rigid nature and high aspect ratio (nanosize) and the strong hydrogen bonding between the filler and the PU matrix. Authors also highlighted that an increase in cellulose content led to self-aggregation and a decrease in properties; however, the incorporation of cellulose does not significantly affect the $T_{g}$. Floros et al. [85] used cellulose with loading rate of $0-2.5 \mathrm{wt} \%$ to reinforce inside the oleic acid-based thermoplastic PU. Authors report that reinforcement of cellulose did not affect $T_{g}$, crystallization behavior, and melting temperature. Authors stated that with $0.5 \mathrm{wt} \%$, cellulose loading shows an increase in elongation at break and tensile strengths of $50 \%$ and $40 \%$, respectively. Apart from that, $\mathrm{He}$ et al. [86] compare cellulose with dialdehyde cellulose at loading levels of $0-25 \mathrm{wt} \%$ as reinforcement for soybean oil-based thermosetting polyurethane composite via the casting method. The authors concluded that oxidized cellulose shows better performance than cellulose due to higher interfacial bonding and small particle size. Saralegi et al. [87] reported that the addition of $0.5 \mathrm{wt} \%$ cellulose nanocrystals to castor oilbased PU did not affect the shape fixity but improved the shape recovery from 50 to $100 \%$ because of the hard phase crystallinity of cellulose. Mosiewicki et al. [88] used micro/nanocellulose to reinforce rapeseed oil-based PU foam. The incorporation of cellulose increased the mechanical properties, water absorption, and rigidity of the resulting foams.

When discussing about biobased materials, the toxicity level of the materials is quite important to study. Based on work conducted by Rezaei Hosseinabadi et al. [89], the authors studied the cytotoxicity level between vegetable oilbased (castor oil) and petroleum-based (polycaprolactone) PU without reinforcement of the nanocellulose. Cytotoxicity of the PU sample was performed by the MTT assay. MTT assay was conducted in cultured L-929 cells on 3, 5, and 7 days. It is reported that cellular viability of polycaprolactone (PCL) is higher compared to castor oil-based PU, and cytotoxicity of PCL-based PU was significantly lower compared to castor oil-based PU. The authors explained that ester linkages in PCL-based PU are highly biocompatible with microorganisms. Apart from biocompatible properties, structure crystallinity and hydrophilicity properties of the films contributed to better cytotoxicity. These enhanced characteristics result in better cell growth and adhesion. It is supported by static contact angle where PCL-based PU $(5.67 \%)$ is more hydrophilic compared to castor oil-based
PU (0.76\%). However, the authors explained that they were very significantly different $(p<0.05)$ between vegetablebased and petroleum-based PUs in terms of cell viability and cytotoxicity. In fact, it is reported that with the addition of nanocellulose, the nanocomposite film obtained will have a better cytotoxicity level. As reported by Khadivi et al. [90], concentration of viable cells increases as reinforced CNC loading increases on polydimethylsiloxane- (PDMS-) based PU nanocomposite films. The CNC was incorporated using the prepolymer method. The cytotoxicity studied from the samples was determined by in vitro cell culturing via seeding human fibroblast (FBS) cells on sample films. It is noted that cell toxicity was inversely proportional to the concentration of viable cells. Based on the authors' work, cell viability was increased from $50-60 \%$ to $90-100 \%$ as CNC increases from 0.1 to $2 \mathrm{wt} \%$. In general, the authors explained that sources of cytotoxicity of the polymer resulted from the presence of impurities, polymer degradation, and interaction of the polymer with intracellular processes as well as cell membrane. Therefore, the authors concluded that moderate cytotoxicity resulted from interaction with intracellular processes or/and interactions of polymers with cell membranes as all monomers completely reacted in the reaction synthesis which lead to no molecule impurities, and no degradation of the polymer happens at lower temperatures which is supported by FTIR and TGA analyses, respectively. On the other hand, Xu et al. [91] studied about the influence of different cotton cellulose nanofiber (c-CNF) loading and degree functionalisation of amino-terminated polydimethylsiloxane $\left(\mathrm{H}_{2} \mathrm{~N}-\mathrm{PDMS}-\mathrm{H}_{2} \mathrm{~N}\right)$ on the cytotoxicity level of polycarbonate diol- (PCDL-) based PU nanocomposite films. 2 sets of samples were successfully prepared; (1) influence of c-CNF was studied by using 0 and $5 \mathrm{wt} \%$ CNF while the molecular weight of $\mathrm{H}_{2} \mathrm{~N}-\mathrm{PDMS}-\mathrm{H}_{2} \mathrm{~N}$ was fixed at 1000 and (2) degree of functionalisation was observed by using 2000 and 4000 molecular weights of $\mathrm{H}_{2} \mathrm{~N}-\mathrm{PDMS}-\mathrm{H}_{2} \mathrm{~N}$ while c-CNF loading was fixed at $5 \mathrm{wt} \%$. Incorporation of $\mathrm{c}-\mathrm{CNF}$ was prepared by the prepolymer method. It is observed that on sample set (1), cell viability increases as much as $3.7 \%$ when loading of c$\mathrm{CNF}$ increases from 0 to $5 \mathrm{wt} \%$. This finding shows good agreement with work conducted by Khadivi et al. [90]. Next, by increasing the molecular weight of $\mathrm{H}_{2} \mathrm{~N}-\mathrm{PDMS}-\mathrm{H}_{2} \mathrm{~N}$ from 1000 to 4000 with fixed $5 \mathrm{wt} \% \mathrm{c}$-CNF, the finding shows increase in cell viability value by as much as $23.1 \%$. This is due to $\mathrm{H}_{2} \mathrm{~N}-\mathrm{PDMS}-\mathrm{H}_{2} \mathrm{~N}$ which introduces excellent biocompatibility properties toward the polymer matrix which supports more cell adhesion and growth. Overall, there is very small difference in terms of cell viability and cytotoxicity between vegetable-based and petroleum-based PUs. Both $\mathrm{CNC}$ and CNF help to increase cell viability and better cytotoxicity of nanocomposite films as loading of cellulose increases, and lastly, cell viability and cytotoxicity can be further improved by introducing biocompatible monomer inside the polymer matrix of nanocomposites. An example of monomer is $\mathrm{H}_{2} \mathrm{~N}-\mathrm{PDMS}-\mathrm{H}_{2} \mathrm{~N}$. Therefore, it is supported that both vegetable oil- and petroleum oil-based PU nanocomposite films can be utilized in medical and food packaging applications as they achieved high cell viability by as much as $90-100 \%$. 
TABle 5: Cellulose nanocomposite application in different industries.

\begin{tabular}{|c|c|c|}
\hline Application field & Product features & References \\
\hline \multirow{3}{*}{ Paper \& packaging } & Intelligent packaging & {$[74,75]$} \\
\hline & Transparent packaging & {$[76]$} \\
\hline & $\begin{array}{l}\text { Ultraviolet screening } \\
\text { packaging }\end{array}$ & {$[77]$} \\
\hline \multirow{3}{*}{ Barrier properties } & Shelf-life extension & \\
\hline & Downgauging of films & {$[78]$} \\
\hline & Oxygen scavenger & \\
\hline \multirow{5}{*}{$\begin{array}{l}\text { Electronics/metallic } \\
\text { particles }\end{array}$} & Time-temperature integrator & \multirow{5}{*}[79]{} \\
\hline & Freshness indicator & \\
\hline & Gas and leakage detector & \\
\hline & Sensors for food monitoring & \\
\hline & $\begin{array}{c}\text { Signal processor for } \\
\text { biochemical pathways }\end{array}$ & \\
\hline \multirow{2}{*}{ Medical } & $\begin{array}{l}\text { Drug delivery and controlled } \\
\text { release }\end{array}$ & {$[4]$} \\
\hline & $\begin{array}{c}\text { Scaffold in tissue engineering } \\
\text { Implants }\end{array}$ & [80] \\
\hline \multirow{3}{*}{$\begin{array}{l}\text { Composites \& } \\
\text { plastics }\end{array}$} & Shelf-life extension & {$[81]$} \\
\hline & Heat resistance & \multirow{2}{*}[82]{} \\
\hline & Dimensional stability & \\
\hline Aerogel & Self-healing material & {$[83]$} \\
\hline
\end{tabular}

\section{Conclusion}

Vegetable oil is an excellent feedstock for biobased polymeric materials. As for now, several technologies have been developed to synthesize these valuable resources into polymer composites, monomers, and polymers with properties comparable to conventional polymers made from petrochemicals. The use of biorenewable feedstocks offers a solution towards volatility in oil price and disruption in oil supplies. For Malaysia, Jatropha oil offers protection against the crisis over the ban issue of import of palm oil into European countries. Jatropha oil shows promising properties as its chemical composition is the same as soybean oil which has been widely utilized in biopolyurethane production. Most of the manufacturers have little initiative to change to biobased plastic because the price of oil is low for now. However, it is predicted by economists that future economic and regulatory conditions will likely cause the cost of fossils to rise. In some regions of the world which lack petroleum reserves and access to refineries, the utilization of vegetable oil for agricultural production may open up to new economic development. A great challenge for vegetable oil-based polymers is in its property gap compared to conventional petroleum-based polymers. As highlighted in this review, a lot of research has been conducted to narrow these property differences. Chemical modification can contribute to the improvement in the mechanical, chemical, and thermal properties. Furthermore, filler sizing could also play an important role. Nano- filler is loaded into vegetable oil-based polymer matrices to increase the performance and render new properties to extend their application area. Some of these fillers can be derived from renewable sources from agriculture or industrial by-product which lead to stable and sustainable polymer composites and can reduce the price of these materials. Even though a lot of research has been made, several challenges still exist. Those challenges include the controversy on polymers made up of food-grade vegetable oil. This food-grade vegetable oil has a problem in controlling its quality due to the heterogeneous nature of vegetable oil. The composition of vegetable oil varies between one another based on many different growth factors, including geographical location, environmental conditions, cultivar selection, and processing techniques. As highlighted throughout this review, different strategies have been developed to synthesize biobased polyols from vegetable oil with one good goal of meeting the cost and property requirements of the marketplace. The mechanical and thermal properties of PU were the most improved properties when reinforced with cellulose, which are the two important criteria for the market to adopt. However, the thermal and mechanical properties need continuous improvement. Tremendous research effort has been made to match the performance of vegetable oil-based PU with petroleum-based, as discussed in this review. Further research and innovation are required to produce costeffective and high-quality vegetable oil-based PUs and broaden their application since vegetable oil appears to be a bright future. Novel PUs synthesized using biobased and renewable materials with improved mechanical and thermal properties are expected to fill the market shelf soon as research efforts in this field are continuously increasing, and Jatropha oil seems the most relevant of all vegetable oils as reviewed.

\section{Data Availability}

No data were used to support this study.

\section{Conflicts of Interest}

The authors declare that they have no conflicts of interest.

\section{Acknowledgments}

The support of this research by the Malaysian Ministry of Higher Education and Universiti Putra Malaysia under the granted GP-IPM (9667100), FRGS (03-01-19-2193FR), and INTROP HICOE (6369110) are gratefully acknowledged.

\section{References}

[1] M. Ozturk, N. Saba, V. Altay et al., "Biomass and bioenergy: an overview of the development potential in Turkey and Malaysia," Renewable and Sustainable Energy Reviews, vol. 79, pp. 1285-1302, 2017.

[2] S. O. A. SaifulAzry, T. G. Chuah, M. T. Paridah, M. M. Aung, and E. S. Zainudin, "17. Green nanocomposites from cellulose nanowhiskers and Jatropha oil-based polyurethane," in 
Cellulose-Reinforced Nanofibre Composites, pp. 391-400, Elsevier Ltd, 2017.

[3] N. James Rubinsin, W. R. W. Daud, S. K. Kamarudin et al., "Optimization of oil palm empty fruit bunches value chain in Peninsular Malaysia," Food and Bioproducts Processing, vol. 119, pp. 179-194, 2020.

[4] A. Sharma, M. Thakur, M. Bhattacharya, T. Mandal, and S. Goswami, "Commercial application of cellulose nanocomposites - a review," Biotechnology Reports, vol. 21, no. 2018, article e00316, 2019.

[5] M. S. Kim, K. M. Ryu, S. H. Lee, Y. C. Choi, and Y. G. Jeong, "Influences of cellulose nanofibril on microstructures and physical properties of waterborne polyurethane-based nanocomposite films," Carbohydrate polymers, vol. 225, article 115233, 2019.

[6] C. Zhang, S. S. Nair, H. Chen, N. Yan, R. Farnood, and F. Li, "Thermally stable, enhanced water barrier, high strength starch bio-composite reinforced with lignin containing cellulose nanofibrils," Carbohydrate polymers, vol. 230, article 115626, 2020.

[7] A. Kaushik, M. Singh, and G. Verma, "Green nanocomposites based on thermoplastic starch and steam exploded cellulose nanofibrils from wheat straw," Carbohydrate Polymers, vol. 82, no. 2, pp. 337-345, 2010.

[8] E. A. Wilman, "Market redirection leakage in the palm oil market," Ecological Economics, vol. 159, pp. 226-234, 2019.

[9] K. M. Carlson, R. Heilmayr, H. K. Gibbs et al., "Effect of oil palm sustainability certification on deforestation and fire in Indonesia," Proceedings of the National Academy of Sciences of the United States of America, vol. 115, no. 1, pp. 121-126, 2018.

[10] P. G. Curtis, C. M. Slay, N. L. Harris, A. Tyukavina, and M. C. Hansen, "Classifying drivers of global forest loss," Science, vol. 361, no. 6407, pp. 1108-1111, 2018.

[11] R. De Chen, C. F. Huang, and S. Hsu, "Composites of waterborne polyurethane and cellulose nanofibers for 3D printing and bioapplications," Carbohydrate Polymers, vol. 212, no. 1, pp. 75-88, 2019.

[12] A. S. A. Hazmi, M. M. Aung, L. C. Abdullah, M. Z. Salleh, and M. H. Mahmood, "Producing Jatropha oil-based polyol via epoxidation and ring opening," Industrial Crops and Products, vol. 50, pp. 563-567, 2013.

[13] M. M. Aung, Z. Yaakob, S. Kamarudin, and L. C. Abdullah, "Synthesis and characterization of Jatropha (Jatropha curcas L.) oil-based polyurethane wood adhesive," Industrial Crops and Products, vol. 60, pp. 177-185, 2014.

[14] S. R. Mustapa, M. M. Aung, A. Ahmad, A. Mansor, and L. TianKhoon, "Preparation and characterization of Jatropha oil-based polyurethane as non-aqueous solid polymer electrolyte for electrochemical devices," Electrochimica Acta, vol. 222, pp. 293-302, 2016.

[15] S. Saalah, L. C. Abdullah, M. M. Aung et al., "Waterborne polyurethane dispersions synthesized from Jatropha oil," Industrial Crops and Products, vol. 64, pp. 194-200, 2015.

[16] M. Desroches, M. Escouvois, R. Auvergne, S. Caillol, and B. Boutevin, "From vegetable oils to polyurethanes: synthetic routes to polyols and main industrial products," Polymer Reviews, vol. 52, no. 1, pp. 38-79, 2012.

[17] G. Lligadas, J. C. Ronda, M. Galià, and V. Cádiz, "Renewable polymeric materials from vegetable oils: a perspective," Materials Today, vol. 16, no. 9, pp. 337-343, 2013.
[18] M. A. Mosiewicki and M. I. Aranguren, "A short review on novel biocomposites based on plant oil precursors," European Polymer Journal, vol. 49, no. 6, pp. 1243-1256, 2013.

[19] D. K. Chattopadhyay and D. C. Webster, "Thermal stability and flame retardancy of polyurethanes," Progress in Polymer Science, vol. 34, no. 10, pp. 1068-1133, 2009.

[20] V. K. Balla, K. H. Kate, J. Satyavolu, P. Singh, and J. G. D. Tadimeti, "Additive manufacturing of natural fiber reinforced polymer composites: processing and prospects," Composites Part B: Engineering, vol. 174, article 106956, 2019.

[21] K. C. Verma and A. K. Gaur, "Jatropha curcas L.: substitute for conventional energy," World Journal of Agricultural Sciences, vol. 5, no. 5, pp. 552-556, 2009.

[22] M. Y. Koh and T. I. M. Ghazi, "A review of biodiesel production from Jatropha curcas L. oil," Renewable and Sustainable Energy Reviews, vol. 15, no. 5, pp. 2240-2251, 2011.

[23] R. Guo, C. Ma, S. Sun, and Y. Ma, "Kinetic study on oxirane cleavage of epoxidized palm oil," Journal of the American Oil Chemists' Society, vol. 88, no. 4, pp. 517-521, 2011.

[24] C. Zhang, T. F. Garrison, S. A. Madbouly, and M. R. Kessler, "Recent advances in vegetable oil-based polymers and their composites," Progress in Polymer Science, vol. 71, pp. 91-143, 2017.

[25] C. Zhang, Y. Xia, R. Chen, S. Huh, P. A. Johnston, and M. R. Kessler, "Soy-castor oil based polyols prepared using a solvent-free and catalyst-free method and polyurethanes therefrom," Green Chemistry, vol. 15, no. 6, pp. 1477-1484, 2013.

[26] Y. Guo, J. H. Hardesty, V. M. Mannari, and J. L. Massingill, "Hydrolysis of epoxidized soybean oil in the presence of phosphoric acid," Journal of the American Oil Chemists' Society, vol. 84, no. 10, pp. 929-935, 2007.

[27] B. Ni, L. Yang, C. Wang, L. Wang, and D. E. Finlow, "Synthesis and thermal properties of soybean oil-based waterborne polyurethane coatings," Journal of Thermal Analysis and Calorimetry, vol. 100, no. 1, pp. 239-246, 2010.

[28] C. S. Wang, L.-T. Yang, B.-L. Ni, and G. Shi, "Polyurethane networks from different soy-based polyols by the ring opening of epoxidized soybean oil with methanol, glycol, and 1,2-propanediol," Journal of Applied Polymer Science, vol. 114, no. 1, pp. 125-131, 2009.

[29] M. Zieleniewska, M. Auguścik, A. Prociak, P. Rojek, and J. Ryszkowska, "Polyurethane-urea substrates from rapeseed oil-based polyol for bone tissue cultures intended for application in tissue engineering," Polymer Degradation and Stability, vol. 108, pp. 241-249, 2014.

[30] M. S. Gaikwad, V. V. Gite, P. P. Mahulikar, D. G. Hundiwale, and O. S. Yemul, "Eco-friendly polyurethane coatings from cottonseed and Karanja oil," Progress in Organic Coatings, vol. 86, pp. 164-172, 2015.

[31] B. Nohra, L. Candy, J. F. Blanco, C. Guerin, Y. Raoul, and Z. Mouloungui, "From petrochemical polyurethanes to biobased polyhydroxyurethanes," Macromolecules, vol. 46, no. 10, pp. 3771-3792, 2013.

[32] Y.-. C. Tu, P. Kiatsimkul, G. Suppes, and F.-. H. Hsieh, "Physical properties of water-blown rigid polyurethane foams from vegetable oil-based polyols," Journal of Applied Polymer Science, vol. 105, no. 2, pp. 453-459, 2007.

[33] P. S. Bailey, "The reactions of ozone with organic compounds," Chemical Reviews, vol. 58, no. 5, pp. 925-1010, 1958. 
[34] R. Criegee, "Mechanism of ozonolysis," Angewandte Chemie International Edition in English, vol. 14, no. 11, pp. 745-752, 1975.

[35] M. He, Y. Sun, H. Cao, D. Han, and J. Hu, "Theoretical study of the ozonolysis of allyl acetate: mechanism and kinetics," Structural Chemistry, vol. 23, no. 1, pp. 201-208, 2012.

[36] J. Li, D. Han, H. Cao, M. Li, and M. He, “Theoretical study on the mechanism and kinetics for the ozonolysis of vinyl propionate," Structural Chemistry, vol. 25, no. 1, pp. 285-291, 2014.

[37] T. S. Omonov, E. Kharraz, and J. M. Curtis, "Ozonolysis of canola oil: a study of product yields and ozonolysis kinetics in different solvent systems," Journal of the American Oil Chemists' Society, vol. 88, no. 5, pp. 689-705, 2011.

[38] Z. S. Petrović, W. Zhang, and I. Javni, "Structure and properties of polyurethanes prepared from triglyceride polyols by ozonolysis," Biomacromolecules, vol. 6, no. 2, pp. 713-719, 2005.

[39] S. Husic, I. Javni, and Z. S. Petrović, “Thermal and mechanical properties of glass reinforced soy-based polyurethane composites," Composites Science and Technology, vol. 65, no. 1, pp. 19$25,2005$.

[40] T. Vanbesien, F. Hapiot, and E. Monflier, "Hydroformylation of vegetable oils and the potential use of hydroformylated fatty acids," Lipid Technology, vol. 25, no. 8, pp. 175-178, 2013.

[41] Z. S. Petrović, O. Bilić, A. Zlatanić et al., "Polyols and polyurethanes from crude algal oil," Journal of the American Oil Chemists' Society, vol. 90, no. 7, pp. 1073-1078, 2013.

[42] G. B. Bantchev, J. A. Kenar, G. Biresaw, and M. G. Han, "Free radical addition of butanethiol to vegetable oil double bonds," Journal of Agricultural and Food Chemistry, vol. 57, no. 4, pp. 1282-1290, 2009.

[43] C. E. Hoyle and C. N. Bowman, "Thiol-ene click chemistry," Angewandte Chemie International Edition, vol. 49, no. 9, pp. 1540-1573, 2010.

[44] A. B. Lowe, "Thiol-ene "click" reactions and recent applications in polymer and materials synthesis," Polymer Chemistry, vol. 1, no. 1, pp. 17-36, 2010.

[45] M. Ionescu, D. Radojčić, X. Wan, Z. S. Petrović, and T. A. Upshaw, "Functionalized vegetable oils as precursors for polymers by thiol-ene reaction," European Polymer Journal, vol. 67, pp. 439-448, 2015.

[46] M. Desroches, S. Caillol, V. Lapinte, R. Auvergne, and B. Boutevin, "Synthesis of biobased polyols by thiol-ene coupling from vegetable oils," Macromolecules, vol. 44, no. 8, pp. 2489-2500, 2011.

[47] Y. Wang, H. Tian, and L. Zhang, "Role of starch nanocrystals and cellulose whiskers in synergistic reinforcement of waterborne polyurethane," Carbohydrate Polymers, vol. 80, no. 3, pp. 665-671, 2010.

[48] S. Miao, L. Sun, P. Wang, R. Liu, Z. Su, and S. Zhang, "Soybean oil-based polyurethane networks as candidate biomaterials: synthesis and biocompatibility," European Journal of Lipid Science and Technology, vol. 114, no. 10, pp. 1165-1174, 2012.

[49] K. P. Ang, C. S. Lee, S. F. Cheng, and C. H. Chuah, "Synthesis of palm oil-based polyester polyol for polyurethane adhesive production," Journal of Applied Polymer Science, vol. 131, no. 6, pp. 1-8, 2014.

[50] S. Miao, S. Zhang, Z. Su, and P. Wang, "Synthesis of bio-based polyurethanes from epoxidized soybean oil and isopropanolamine," Journal of Applied Polymer Science, vol. 127, no. 3, pp. 1929-1936, 2013.
[51] H. Bakhshi, H. Yeganeh, S. Mehdipour-Ataei, M. A. Shokrgozar, A. Yari, and S. N. Saeedi-Eslami, "Synthesis and characterization of antibacterial polyurethane coatings from quaternary ammonium salts functionalized soybean oil based polyols," Materials Science and Engineering: C, vol. 33, no. 1, pp. 153164, 2013.

[52] A. Pei, J. M. Malho, J. Ruokolainen, Q. Zhou, and L. A. Berglund, "Strong nanocomposite reinforcement effects in polyurethane elastomer with low volume fraction of cellulose nanocrystals," Macromolecules, vol. 44, no. 11, pp. 44224427, 2011.

[53] V. Kupka, F. Ansari, H. Tang et al., "Well-dispersed polyurethane/cellulose nanocrystal nanocomposites synthesized by a solvent-free procedure in bulk," Polymer Composites, vol. 40, no. S1, pp. E456-E465, 2019.

[54] P. Khadivi, M. Salami-Kalajahi, H. Roghani-Mamaqani, and R. Lotfi Mayan Sofla, "Fabrication of microphase-separated polyurethane/cellulose nanocrystal nanocomposites with irregular mechanical and shape memory properties," Applied Physics A: Materials Science \& Processing, vol. 125, no. 11, pp. 1-10, 2019.

[55] I. Omrani, A. Farhadian, N. Babanejad, H. K. Shendi, A. Ahmadi, and M. R. Nabid, "Synthesis of novel high primary hydroxyl functionality polyol from sunflower oil using thiolyne reaction and their application in polyurethane coating," European Polymer Journal, vol. 82, pp. 220-231, 2016.

[56] F. Yu, P. Saha, P. W. Suh, and J. K. Kim, "Green polyurethane from dimer acid based polyether polyols: synthesis and characterization," Journal of Applied Polymer Science, vol. 132, no. 5, pp. 1-9, 2015.

[57] C. Zhang, S. A. Madbouly, and M. R. Kessler, "Biobased polyurethanes prepared from different vegetable oils," ACS applied materials \& interfaces, vol. 7, no. 2, pp. 1226-1233, 2015.

[58] K. Karadeniz, Y. Çalıkoğlu, and M. Y. Sen, “A novel polyurethanes from epoxidized soybean oil synthesized by ring opening with bifunctional compounds," Polymer Bulletin, vol. 74, no. 7, pp. 2819-2839, 2017.

[59] S. Caillol, M. Desroches, G. Boutevin, C. Loubat, R. Auvergne, and B. Boutevin, "Synthesis of new polyester polyols from epoxidized vegetable oils and biobased acids," European Journal of Lipid Science and Technology, vol. 114, no. 12, pp. 14471459, 2012.

[60] X. Kong, G. Liu, H. Qi, and J. M. Curtis, "Preparation and characterization of high-solid polyurethane coating systems based on vegetable oil derived polyols," Progress in Organic Coatings, vol. 76, no. 9, pp. 1151-1160, 2013.

[61] C. Zhang, R. Ding, and M. R. Kessler, "Reduction of epoxidized vegetable oils: a novel method to prepare bio-based polyols for polyurethanes," Macromolecular Rapid Communications, vol. 35, no. 11, pp. 1068-1074, 2014.

[62] T. F. Garrison and M. R. Kessler, Plant Oil-Based Polyurethanes, Elsevier Inc., 2015.

[63] H. Bakhshi, H. Yeganeh, and S. Mehdipour-Ataei, "Synthesis and evaluation of antibacterial polyurethane coatings made from soybean oil functionalized with dimethylphenylammonium iodide and hydroxyl groups," Journal of Biomedical Materials Research Part A, vol. 101, no. 6, pp. 1599-1611, 2013.

[64] R. Chen, C. Zhang, and M. R. Kessler, "Polyols and polyurethanes prepared from epoxidized soybean oil ring-opened by polyhydroxy fatty acids with varying oh numbers," Journal of Applied Polymer Science, vol. 132, no. 1, pp. 1-10, 2014. 
[65] F. H. Yeoh, C. S. Lee, Y. B. Kang, S. F. Wong, and S. F. Cheng, "One-pot synthesis of palm oil-based polyester polyol for production of biodegradable and biocompatible polyurethane," Journal of Applied Polymer Science, vol. 135, no. 44, article 46861, pp. 1-16, 2018.

[66] P. Alagi, Y. J. Choi, J. Seog, and S. C. Hong, "Efficient and quantitative chemical transformation of vegetable oils to polyols through a thiol-ene reaction for thermoplastic polyurethanes," Industrial Crops and Products, vol. 87, pp. 7888, 2016.

[67] Y. Feng, H. Liang, Z. Yang et al., “A solvent-free and scalable method to prepare soybean-oil-based polyols by thiol-ene photo-click reaction and biobased polyurethanes therefrom," ACS Sustainable Chemistry \& Engineering, vol. 5, no. 8, pp. 7365-7373, 2017.

[68] P. Alagi, Y. J. Choi, and S. C. Hong, "Preparation of vegetable oil-based polyols with controlled hydroxyl functionalities for thermoplastic polyurethane," European Polymer Journal, vol. 78, pp. 46-60, 2016.

[69] C. Mokhtari, F. Malek, S. Caillol, and C. Negrell, "Synthesis of bio-based polyurethanes from Jojoba oil," European Journal of Lipid Science and Technology, vol. 120, no. 3, 2018.

[70] M. Ionescu, D. Radojčić, X. Wan, M. L. Shrestha, Z. S. Petrović, and T. A. Upshaw, "Highly functional polyols from castor oil for rigid polyurethanes," European Polymer Journal, vol. 84, pp. 736-749, 2016.

[71] M. Comí, G. Lligadas, J. C. Ronda, M. Galià, and V. Cádiz, "Synthesis of castor-oil based polyurethanes bearing alkene/alkyne groups and subsequent thiol-ene/yne post-modification," Polymer, vol. 103, pp. 163-170, 2016.

[72] H. Liang, Y. Feng, J. Lu et al., "Bio-based cationic waterborne polyurethanes dispersions prepared from different vegetable oils," Industrial Crops and Products, vol. 122, pp. 448-455, 2018.

[73] Y. Shen, J. He, Z. Xie, X. Zhou, C. Fang, and C. Zhang, "Synthesis and characterization of vegetable oil based polyurethanes with tunable thermomechanical performance," Industrial Crops and Products, vol. 140, article 111711, 2019.

[74] H. P. S. Abdul Khalil, Y. Davoudpour, C. K. Saurabh et al., “A review on nanocellulosic fibres as new material for sustainable packaging: process and applications," Renewable and Sustainable Energy Reviews, vol. 64, pp. 823-836, 2016.

[75] H. M. C. Azeredo, M. F. Rosa, and L. H. C. Mattoso, "Nanocellulose in bio-based food packaging applications," Industrial Crops and Products, vol. 97, pp. 664-671, 2017.

[76] S. Boufi, I. González, M. Delgado-Aguilar, Q. Tarrès, M. À. Pèlach, and P. Mutjé, "Nanofibrillated cellulose as an additive in papermaking process: a review," Carbohydrate Polymers, vol. 154, pp. 151-166, 2016.

[77] S. H. Osong, S. Norgren, and P. Engstrand, "Processing of wood-based microfibrillated cellulose and nanofibrillated cellulose, and applications relating to papermaking: a review," Cellulose, vol. 23, no. 1, pp. 93-123, 2016.

[78] N. Lavoine, I. Desloges, A. Dufresne, and J. Bras, "Microfibrillated cellulose - its barrier properties and applications in cellulosic materials: a review," Carbohydrate Polymers, vol. 90, no. 2, pp. 735-764, 2012.

[79] M. Kaushik and A. Moores, "Review: nanocelluloses as versatile supports for metal nanoparticles and their applications in catalysis," Green Chemistry, vol. 18, no. 3, pp. 622-637, 2016.
[80] Y. Xue, Z. Mou, and H. Xiao, "Nanocellulose as a sustainable biomass material: structure, properties, present status and future prospects in biomedical applications," Nanoscale, vol. 9, no. 39, pp. 14758-14781, 2017.

[81] M. H. Mousa, Y. Dong, and I. J. Davies, "Recent advances in bionanocomposites: preparation, properties, and applications," International Journal of Polymeric Materials and Polymeric Biomaterials, vol. 65, no. 5, pp. 225-254, 2016.

[82] I. Siró and D. Plackett, "Microfibrillated cellulose and new nanocomposite materials: a review," Cellulose, vol. 17 , no. 3 , pp. 459-494, 2010.

[83] K. J. De France, T. Hoare, and E. D. Cranston, "Review of hydrogels and aerogels containing nanocellulose," Chemistry of Materials, vol. 29, no. 11, pp. 4609-4631, 2017.

[84] Z. Gao, J. Peng, T. Zhong, J. Sun, X. Wang, and C. Yue, "Biocompatible elastomer of waterborne polyurethane based on castor oil and polyethylene glycol with cellulose nanocrystals," Carbohydrate Polymers, vol. 87, no. 3, pp. 2068-2075, 2012.

[85] M. Floros, L. Hojabri, E. Abraham et al., "Enhancement of thermal stability, strength and extensibility of lipid-based polyurethanes with cellulose-based nanofibers," Polymer Degradation and Stability, vol. 97, no. 10, pp. 1970-1978, 2012.

[86] M. He, J. Zhou, H. Zhang, Z. Luo, and J. Yao, "Microcrystalline cellulose as reactive reinforcing fillers for epoxidized soybean oil polymer composites," Journal of Applied Polymer Science, vol. 132, no. 36, pp. 6-13, 2015.

[87] A. Saralegi, M. L. Gonzalez, A. Valea, A. Eceiza, and M. A. Corcuera, "The role of cellulose nanocrystals in the improvement of the shape-memory properties of castor oil-based segmented thermoplastic polyurethanes," Composites Science and Technology, vol. 92, pp. 27-33, 2014.

[88] M. A. Mosiewicki, P. Rojek, S. Michałowski, M. I. Aranguren, and A. Prociak, "Rapeseed oil-based polyurethane foams modified with glycerol and cellulose micro/nanocrystals," Journal of Applied Polymer Science, vol. 132, no. 10, pp. 9-12, 2015.

[89] S. Rezaei Hosseinabadi, A. Parsapour, S. Nouri Khorasani et al., "Wound dressing application of castor oil- and CAPAbased polyurethane membranes," Polymer Bulletin, vol. 77, no. 6, pp. 2945-2964, 2020.

[90] P. Khadivi, M. Salami-Kalajahi, and H. Roghani-Mamaqani, "Evaluation of in vitro cytotoxicity and properties of polydimethylsiloxane-based polyurethane/crystalline nanocellulose bionanocomposites," Journal of Biomedical Materials Research Part A, vol. 107, no. 8, pp. 1771-1778, 2019.

[91] C. A. Xu, B. Nan, M. Lu et al., "Effects of polysiloxanes with different molecular weights on in vitro cytotoxicity and properties of polyurethane/cotton-cellulose nanofiber nanocomposite films," Polymer Chemistry, vol. 11, no. 32, pp. 5225-5237, 2020 . 